\title{
Pseudoxanthomaelasticum with congestive heart failure: A case report
}

\author{
Mohamed K A Gasim MD ${ }^{1}$, Faisal A Suleiman MRCP ${ }^{2}$, M S Alkhaleefa FRCP ${ }^{3}$, Eshraga A Faragalla MD $^{4}$
}

Pseudoxanthomaelasticum (PXE) is a rare systemic disease of connective tissue primarily affecting the skin, retinae, and cardiovascular system. Clinically it has high hetrogenicity in age of onset, extent and severity of disease. Its cardiovascular effect has a wide clinical spectrum extending from mental fatigue to early death from myocardial infarction. Very rarely it may present with gastrointestinal haemorrhage. It has no specific treatment. However, adjustments of the life stile are important to reduce morbidity. Moreover, first degree relatives should be carefully examined for cutaneous and ophthalmic features of this disease.

Here we describe one case of Pseudoxanthoma Elasticum.

\section{Case report:}

A 14-year-old female presented in March 20th 2004 with dry cough and dyspnoea, for eight months.

She had orthopnea, stapping right side chest pain which is aggravated by coughing. She had no fever, haemoptasis, paroxysmal nocturnal dyspnoea, wheezes, syncope, palpitations or swelling of the lower limbs. Her bowel habits and micturition were normal. There is no past history of tonsillitis, joint pain or chronic cough.

On physical examination: She was breathless, pulse was normal. BP 90/60 JVP was raised and had no palpable cervical lymph node. Examination of the heart was normal apart from a third heart sound [gallop rhythm]. Her trachea was deviated to the right and there were fine crepitations at the bases of the lungs. The liver was enlarged and tender. CNS examination was normal including fundoscopy.

1- Associate Professor. Correspondence: to Dr. Mohd Kheir Awad Gasim.

2- Associate Prof. Faculty of Medine, University of Khartoum,

3- Associate Prof. Faculty of Medicine Omdurman Islamic University.4- Pathologist, Ahmed Gasim Cardiac Centre.
Skin examination showed maculopapular skin rash- punctuated chicken skin- seen at the axilla and the neck it is not itching or scaling (fig 1).

\section{Investigations:}

HB 12grm/dl, PCV 36, WBC 4800/cu.mm polymorphs $70 \%$, lymphocytes $25 \%$ monocytes 4\%, eosnophils 1\% ESR.86/hr. Urinalysis was normal. BUN 21mg/dl. Na 130meq/L, K 3,5/L $\mathrm{Ca} 7,4 \mathrm{mg} / \mathrm{dl}$.

Chest X-ray: showed cardiomegaly, with calcification of the myocardium and mild pulmonary congestion (fig 2).

ECG: showed evidence of LBBB.(Fig 3)

Echo: pulsed wave doppler of the mitral valve shows mild mitral regergitation and features of diastolic dysfunction as tall E-wave and short Awave at 2-dimentional left axes view showed calcification of the septum, aortic root, aortic wall and the posterior wall of the left atrium(LA). The 2-dimentional apical 4 champer view showed calcification of the septum and lateral wall of the left ventricle (LV) seen as hyperechoeic areas. Calcification of the septum and posterior wall is also seen by the M-mode view fig (4).

Histopathology of skin biopsy taken from the neck revealed calcified black areas (black arrows) altered by elastic tissue fibers in the dermis.[Fig. 5a and 5b] ( H\&E stain X 40 and H\&E stain X 40 respectively). Special stain for elastic fibres (Vangesin stain) revealed black streaks of normal elastic fibers (green arrow) with other degenerated elastic fibers (blue arrow) (fig. 5c X40). These findings confirm the diagnosis of pseudoxanthomaelasticum

\section{Discussion:}

Pseudoxathoma elasticum which is an inherited connective tissue disorder is characterized by progressive calcification and fragmentation of elastic tissue fibers in the skin, retina and the cardiovascular system. Calcification of the elastic media and intima of the blood vessels leads to angina, claudication and hypertension due to renal artery involvement. PXE was first described by Rigal ${ }^{1}$ in 1881 and the term pseudoxanthoma elasticum was first 
Fig 1: Skin examination showed maculopapular skin rash like punctuate chicken skin seen at the axilla and the neck but it is not itching
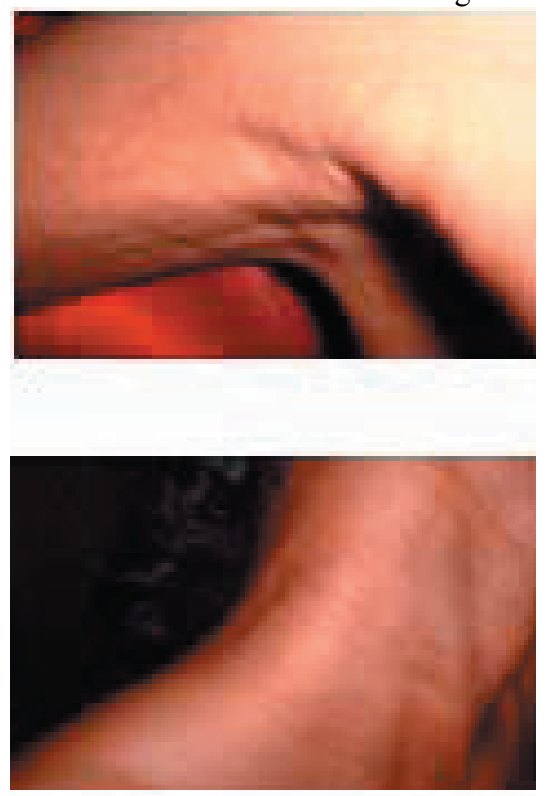

Fig 2: Chest X-ray: showed cardiomegaly, with calcification of the myocardiu and mild pulmonary congestion
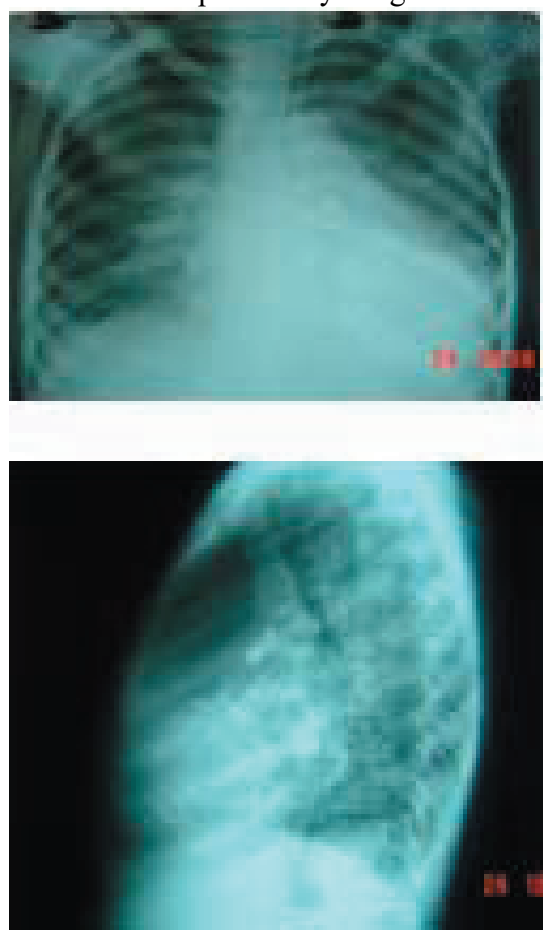

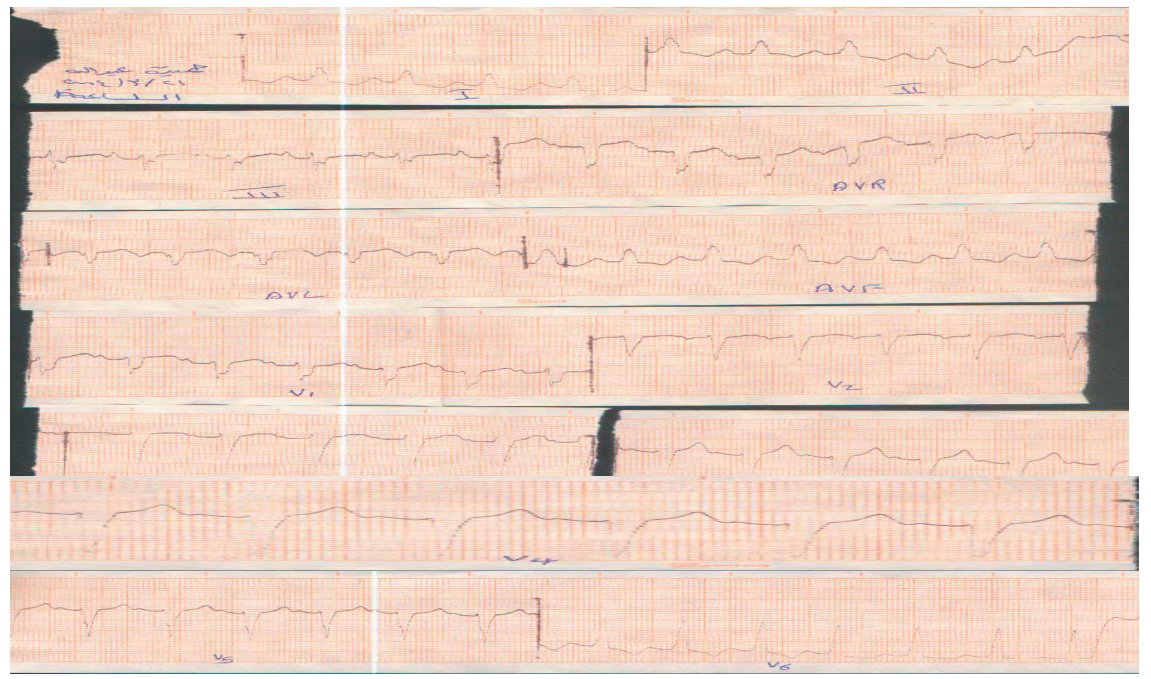

Fig 3: ECG: shows evidence of LBBB. 
introduced by Darier ${ }^{2}$ in 1896 when he discovered the abnormality in the elastic tissue histologically. Autopsy findings of endocardial thickening in PXE with degeneration and calcification of the elastic fibres was reported in the early seventies of the last century ${ }^{3}$.

Fig 4: The Echocardiographic changes
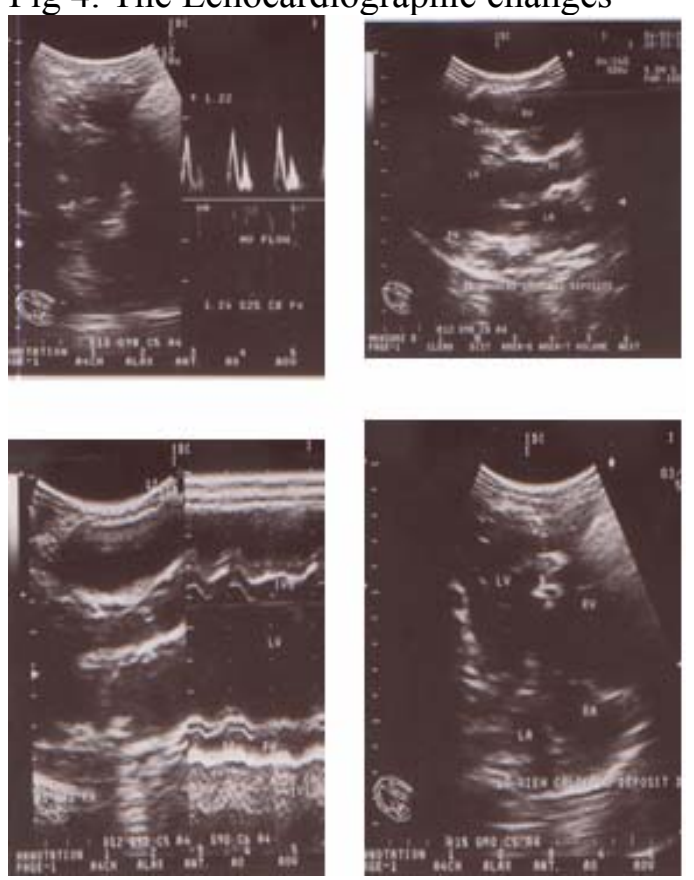

This patient was diagnosed clinically to have congestive heart failure. The presence of the skin lesions raised the possibility of PXE. Calcification of the myocardium as seen in the chest X-ray and echocardiography is not reported in PXE. The calcification of the myocardium is demonstrated by radiology of chest specially the lateral view and by echocardiography. (Fig, 2 \& Fig.4). 2 dimensional echo views showed calcification of the LV free wall, interventricular septum (IVS), aortic wall and atrial wall. M-mode view showed calcification of the IVS and posterior wall. Excessive calcification of the heart was not reported before. However, calcification of the valves $^{4}$, area of infarction ${ }^{5}$ and coronary artery was previously reported ${ }^{6,7}$

Our patient was dyspnoeic and orthopnoeic due to diastolic dysfunction which is demonstrated by the Doppler flow of the MV as increase in amplitude of the $\mathrm{E}$ velocity and decrease in A velocity. The ECG showed LBBB which reflects involvement of the conductive tissue due to extensive myocardial damage. This finding is in keeping with the findings of Nguyen
LD et $\mathrm{al}^{8}$ who postulated the cause to be silent myocardial ischaemia resulting from coronary involvement and/or direct consequences of ultrastructural defects of the elastic tissue of the heart. PXE is characterised by mineralization and fragmentation of the elastic fibres (so called elastorrhexia) and mutation in the ABCC (ATP binding cassette subtype $C$ number 6 gene in at least $80 \%$ of cases 9 . The disease should be suspected at all age groups particularly young patients like ours and in different races ${ }^{10,11}$. $\mathrm{R} 1141 \mathrm{X}$ mutation is by far the most common mutation; it has been identified in $30 \%$ of all PXE patients in the Netherland ${ }^{11}$. PXE was reported to be inherited as autosomal recessive ${ }^{12}$.

Other features of PXE are seen in the skin as maculopapular rash which is neither itching nor scaling, and it looks like punctuated chicken skin as seen at the axilla of our patient. Either skin biopsy or mollicular studies can be performed to confirm the disease. Our patient was not able to proceed for mollicular studies.

Ectopic calcification of a variety of tissues including the heart and arteries is a common manifestation of secondary hyperparathyroidism which is a frequent complication of chronic renal failure. Our patient has neither clinical nor biochemical evidence of renal disease. Ectopic calcification may involve the sinoatrial node, atrioventricular node, ventriclar myocardium, the valve annulus and cusps. About $8 \%$ of the ectopic calcification involves interventricular septum Also, calcifications of the valves take place in rheumatic fever, congenital bicuspid aortic valve and in elderly patients due to degenerative changes. This patient is young, has no history of rheumatic fever and her aortic valve was normal.

Myocardial calcifications may occur in patient who have sustained sizeable myocardial infarction, and have survived more than 6 years after infarction which is not the condition here.. Mural thrombi can also get calcified and cardiac tumours such as rhabdomyomas and endothliomas may rarely calcify. Furthermore, calcification of the pericardium is seen in constrictive pericarditis. The importance of this case come from two points; the first one is that she presented with heart failure which is rarely caused by myocardial calcification per say. The second one is that extensive calcification of the moyocardium as seen here was not reported either in association with pseudoxanthoma elasticum or with other known causes of myocardial calcification. 
Fig 5a, b and c: Histopathology shows pseudoxanthomaelasticum

a

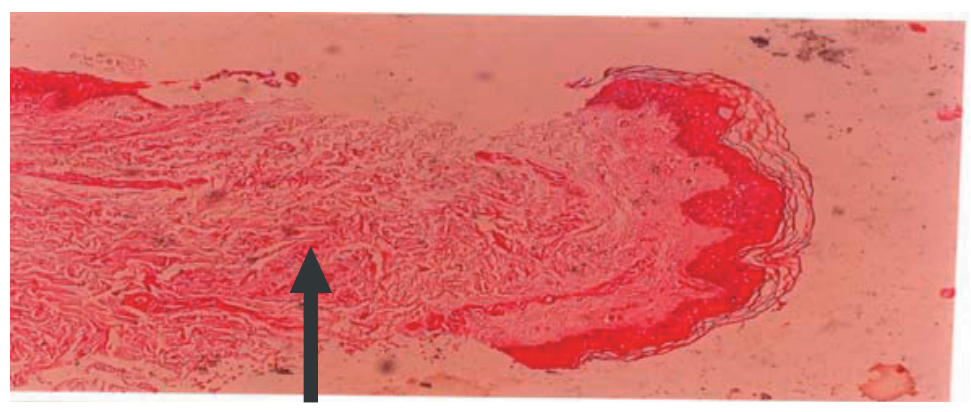

b
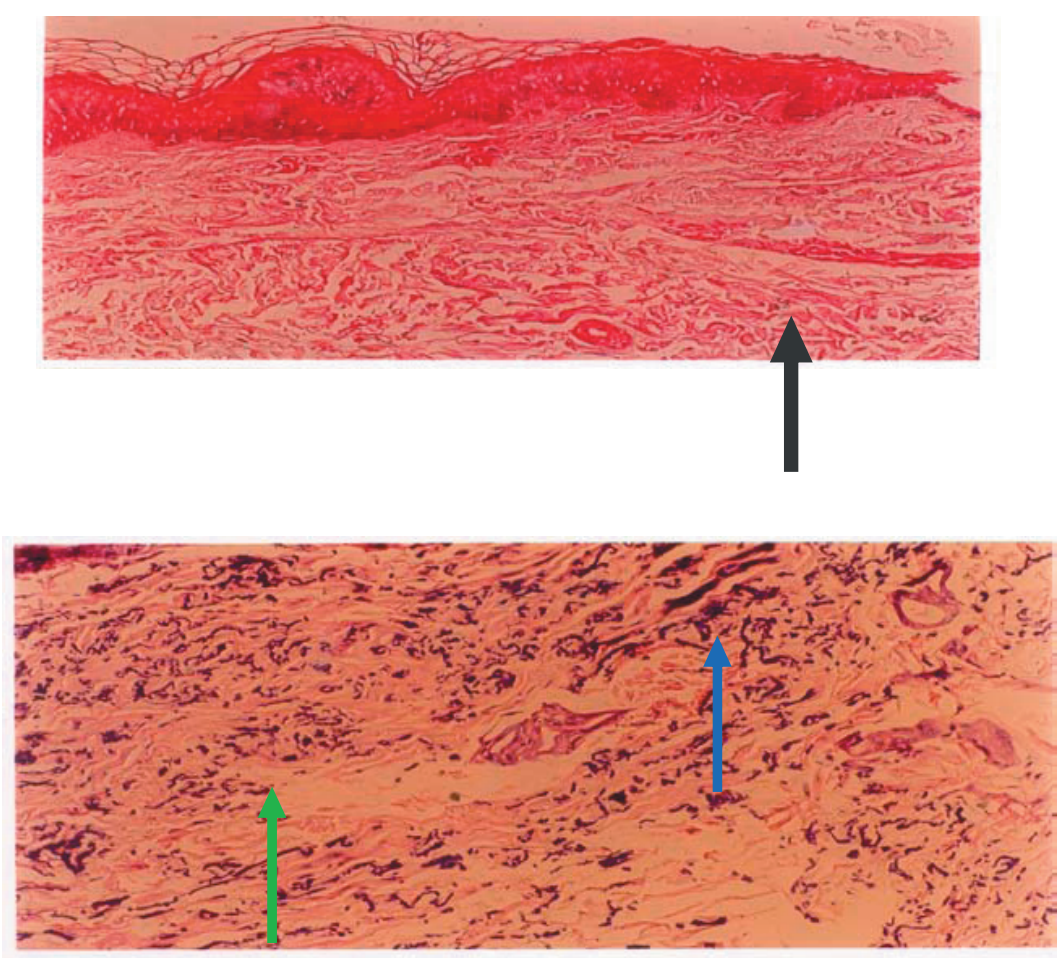

\section{References}

1- Rigal D. Observation pour server a L'histoire de la Cheloide diffuse

Xanthelamique. Ann. Derm. Syph. 1881; 2: 491

2- Darier J. Pseudoxanthoma elasticum. Monatshefte Prakt. Derm.1896; 23: 609-614.

3- McKusick VA. Hertable Disorders of Connective tissue. St. Louis CV Mosby (Pub.) $4^{\text {th }}$ ed. 1972: 475-520.

4-Leppert JA. White CS; Massive calcification of the aortic valve detected incedently, prevalence and clinical significance. AJR AMJ Roentgenol, 1995 (1) 73-7(M)
5- Kiec-Wilk B, Surdacki A, Dernbinska-Kiec et al. Acute myocardial infarction and a new ABCC6 in a 16 -year-old boy with pseudoxanthoma elasticum. Int. J. Cardiol. 2006; 17

6- Trip MD, Smulders YM, Wegman JJ et al. Frequent mutation in the ABCC6 gene(R1141X) is associated with a strong disease in the prevalence of coronary artery disease. Circulation 2002; 106(7): 773-5.

7- Agastan AS. Quantification of coronary artery calcification and associated coronary artery disease in a symptomatic young men. JAM.cardio.1992.19:1167- 72. 
8- Nguyen LD, Terbah M, Daudon P, Martin L. Am J cardiol 2006; 97(10): 1535-7.

9- Chassaing N, Martin L, Calvas P. Pseudoxanthoma elasticum: A clinical, pathological and genetic update including 11 novel ABCC6 mutations. J.Med. genet. 2005; 42 (12): 881-92.

10- Przybojewski JZ, Martiz F, Tiedt FA et al Pseudoxanthoma elasticum wit $\mathrm{h}$ cardiac involvement: A cas e report and review of the literature. S. Afr. Med. J. 1981; 59(8): 264-75.

11- Bergen AA, Plomp AS, gorgels TG et al. From gene to disease; Pseudoxanthomaelasticum and the ABCC6 gene. 2004; 148(32): 1586-9.

12- Ringpfeil F, McGuigan K, Fuchsel L et al. Pseudoxanthoma elasticum is a recessive disease characterised by compound hetrozygosity. J Inves. Dermatol. 2006; 126: 7045. 